\title{
Research and Application of the Property of Conductive Knitted Fabrics
}

\author{
Liwen Li, Kun Yang, Guangli Song, Liang Zhang \& Juan Guo \\ School of Textiles, Tianjin Polytechnic University, Tianjin 300160, China \\ Tel: 86-22-2452-8287 E-mail: kunyang@tjpu.edu.cn
}

The research is financed by the Application Fundamental Research Plan Fund of Tianjin Municipal Science and Technology Commission (No. 07JCYBJC16100). (Sponsoring information)

\begin{abstract}
Traditional knitted fabrics have been extensively applied in dresses and home decoration, and in recent years, the applications of the fabrics knitted by new technologies and new materials also increase in other fields. The conductive fiber knitted fabrics was used in the article, and its electric properties under transverse stretching were tested and researched. Based on the electric model of $1 \times 1$ rib fabrics, the silver-coasted conductive yarns were adopted to knit the conductive fabrics, and the stretching test was conducted, and the relationship between stretching and resistance was primarily analyzed. Then, a product prototype, an electronic organ with force sensitive keyboard was designed. The test result reveals that it works well.
\end{abstract}

Keywords: Conductive knitted fabrics, Stretching, Resistance, $1 \times 1$ rib

In recent years, the research and application of conductive fibers have been gradually mature, and the conductive fibers can not only eliminate static and absorb electromagnetic wave, but can be used in the detection technologies such as the detection and transmission of electric signals. As a kind of important intelligent material, the conductive fibers have been extensively concerned by foreign and domestic material industry, and possess bright application foreground in dresses, sensors and other industries (Li, 2003). Some literature had acquired the relation between the resistance and density of the flat conductive knitting fabrics with the single-axis stretching through test and theoretical analysis, and studied the impacts of various factors on the conductive knitted fabrics, and established the theoretical model (Yang, 2006). Good flexibility and stretching property of the knitted fabrics make the sensors to fit measuring the large stretching stress and possess more extensive application range. The fabric texture, loop transfer, contact resistance and loading speed of the conductive knitted fabrics are the factors to impact the resistance of the fabrics (Yang, 2008 \& Zhang, 2005). These scholars studied the application of conductive knitted fabrics, and most of them aimed at the plain knitted fabrics, and few of them studied the conductive knitted fabrics with other textures, because other textures such as $1 \times 1$ rib texture has different geometric structure and electric property with the plain knitted texture. Therefore, it is necessary to further study the electric conductivity of other conductive knitted fabrics in large transverse stretching. In the article, the stretching test of the conductive knitted fabrics $(1 \times 1 \mathrm{rib})$ was made to obtain the stretching change rule of fabric resistance, and relative properties were discussed simply, and the applied product prototype was designed based on above researches.

\section{Basic theories}

The theoretical research of conductive knitted fabrics is based on following hypothesis, i.e. the unit length of conductive fiber resistance is invariable, and isn't impacted by the stretching and distortion in certain stretching range (Xue, 2004). When the fabrics are drawn, the transfers of various loops are consistent, i.e. the yarns in the loop transfer from the arc part to the pole part, and under the premise that the loop length is invariable, the resistances of the art part and the pole part change with the changes of lengths, so the network resistances of the whole fabrics will correspondingly change. Figure 1 is the geometric structure unit of the $1 \times 1$ rib conductive fabrics loop, and Figure 2 is the corresponding resistance unit model, and $\mathrm{R}_{\mathrm{L} 1}, \mathrm{R}_{\mathrm{L} 2}$ and $\mathrm{R}_{\mathrm{L} 3}$ denotes the length resistances, and Rc denotes the contact resistance in the unit.

The electrics model of $1 \times 1$ rib conductive knitted fabrics can be established based on Ohm's Law and Kirchhoff's Law, and the formula (1) is the matrix expression of various loop currents.

$$
\left[R_{k, j}^{*}\right]\left[i_{k}\right]=\left[U_{j}\right] \quad(k=1,3,5, \ldots, m ; j=1,2,3, \ldots, n)
$$


Where, $\left[R_{k, j}^{*}\right]$ denotes the matrix expression of the $\mathrm{k}$ 'th row and the $\mathrm{j}$ 'th line in the network circuit model, $i_{k}$ denotes the loop current of the mesh in the circuit model, $U_{j}$ is the exterior voltage of the circuit, and $m$ is odd number and $n$ is natural number.

$$
\left[R_{k, j}^{*}\right]=\left(\begin{array}{ccccccccccc}
R_{1,1}+R_{1,2}+R_{2,1} & -R_{1,2} & 0 & 0 & \ldots & -R_{2,1} & 0 & 0 & \ldots & \ldots & -R_{1,1} \\
-R_{1,2} & R_{1,2}+R_{1,3}+R_{2,2} & -R_{1,3} & 0 & \ldots & 0 & -R_{2,2} & 0 & \ldots & \ldots & 0 \\
0 & -R_{1,3} & R_{1,3}+R_{1,4}+R_{2,3} & -R_{1,4} & \ldots & 0 & 0 & -R_{2,3} & \ldots & \ldots & 0 \\
\ldots & \ldots & \ldots & \ldots & \ldots & \ldots & \ldots & \ldots & \ldots & \ldots & \ldots \\
\ldots & \ldots & \ldots & \ldots & \ldots & \ldots & \ldots & \ldots & \ldots & \ldots & \ldots \\
\ldots & \ldots & \ldots & \ldots & \ldots & \ldots & \ldots & \ldots & \ldots & \ldots & \ldots \\
-R_{1,1} & 0 & 0 & 0 & \ldots & 0 & \ldots & 0 & \ldots & \ldots & R_{\mathrm{l}, 1}+R_{3,1}+R_{5,1}+R_{7,1}+R_{9,1}+\ldots+R_{m-2,1}+R_{m, 1}
\end{array}\right)
$$

$$
\left[U_{j}\right]=\left(\begin{array}{c}
0 \\
0 \\
0 \\
\cdots \\
\cdots \\
\cdots \\
U
\end{array}\right)
$$

Through computing $\left[R_{k, j}^{*}\right]$ in (1), the total current $i_{\left(\frac{m+1}{2}\right) \times n+1}$ of the whole loop can be obtained, and $\left(\frac{m+1}{2}\right) \times n+1$ is the amount of loop.

\section{Stretching electric conductivity test of conductive knitted fabrics}

The rib texture is collocated by the transverse line of the obverse loop and the transverse line of the reversed loop alternately. The sinking arc linking the obverse loop and the reversed loop bears large bending and torsions, and the loop transverse lines on each face are adjoined each other. Therefore, when the transverse stretching happens, the fabrics will have larger flexibility than the plain knitted fabrics. In the research, the most representative $1 \times 1$ rib textures were selected to knit the conductive fiber fabrics.

\subsection{Experiment materials and equipments}

Because of the limitation of the knitted property of conductive fibers, the Flying Tiger hand-operated flat knitting machine was selected based on the results of primary test research (Zhang, 2008) and comparison. The machine gauge is E9, i.e. 9npi. The raw materials were silver-coated conductive fibers. Table 1 shows the specs of conductive fibers and conductive knitted fabrics.

In the experiment, the LK-1 knitted fabrics stretching property tester was used to stretch the fabrics (seen in Figure 3), and the stretching speed was $30 \mathrm{~cm} / \mathrm{min}$, and the initial tension was $0.5 \mathrm{~N}$. The resistance change of the conductive fabrics was measured and recorded by the Agilent Digit Multimeter connecting with the computer. The instrument connection is seen in Figure 4.

\subsection{Experiment test and result analysis}

The current in the experiment was obtained by measuring the resistance transversely passing the fabrics, and Figure 5 is the relation between the stretching rate $(\varepsilon)$ and the resistance $(\mathrm{R})$ in the stretching process of the conductive fabrics.

In Figure 5, in the whole stretching process, the resistance of the conductive fiber fabrics changed obviously. The relative resistance of the conductive knitted fabrics reduced with the increase of $\varepsilon$, and the electric conductivity increased correspondingly, which was close to the linear relation in certain strain range. When the stretch achieved certain value, the resistance of the fabrics was stable basically, and the electric conductivity of fabrics achieved a relatively stable state.

\section{Application of the conductive knitted fabrics}

\subsection{Design scheme}

Above theoretical analysis and experiment result indicated that the resistance of conductive knitted fabrics changed with the stretching length. Based on that conclusion, the electric organ was converted in the experiment. The volume controller of the electric organ was a controllable resistor in fact, and when the volume controller was turning, the resistance of the controllable resistor would change. The change of the resistance would change the voice intensity of the trumpet. So when the volume control knob was turning, the sound of the electric organ would change with that. 
Connect the silver-coated conductive fiber knitted fabrics with the circuit of the electric organ, and stretch the conductive fiber fabrics at the connecting place by the knob form to change the resistance in the circuit and change the current, and accordingly change the loudness of the electric organ.

According to the experiment result, it was ideal to control the stretching resistance change of the conductive knitted fabrics in $30 \%$.

\subsection{Circuits assembly}

Figure 6 is the circuit diagram of the electric organ, and various components are connected by the circuit principle diagram, and Figure 7 is the converted electric organ $(6 \mathrm{~V})$.

\subsection{Test result and analysis}

The research reflected the change of the resistance of the whole circuit by measuring the voltage change of two ends of the electric organ, and the current change.

From the test result (Table 2), in the whole stretching process, because of the stretching, the resistance of fabrics decreased, so the current of the whole circuit changed. In the circuit, to press the key-press could stretch the conductive fiber to change the resistance of the whole circuit, and the result could basically accord with the initial hypothesis of this research.

The silver-coated fibers are the yarns with silver-coated surface, and different materials have different stretching properties of the yarn and metallic-membrane plating when the fibers were stretching. The anti-stretching performance is stronger than the performance of the silver-coated surface, and when the stretch achieves a certain extent, the conductive fiber will be stretched, and its exterior silver-coated surface will be cracked, so the resistance will increase, and the current will first increase and reduce later, which showed that in actual application, the stretching flexible range and the application limitation of fabrics with different materials should be considered.

\section{Conclusions}

In the research, the stretching test and theoretical analysis of the conductive fiber knitted fabrics indicated that with the increase of stretching and distorting, the resistance of conductive knitted fabrics reduced correspondingly, and when the stretching achieved certain degree, the electric conductivity of fabrics achieved a relatively stable state. Combining with the conductivity of conductive fiber and the stretching property of knitted fabrics, the knitted conductive fabrics were connected into the circuit of the electric organ, and under different pressing states (different stretching degrees), the current in the circuit would change with the change of resistance, and the loudness of the electric organ would also change. But it needs further research to exactly control the volume of the electric organ.

\section{References}

Li, W. \& Zhuang, Q.L. (2003). Development of Electrically Conductive Fibers and Its Smart Textiles. Technical Textiles. No.8.

Xue, P., Tao, X. M., Yu, T. X., Kwok, K. \& Leung, S. (2004). Electro-mechanical behavior and mechanistic analysis of fiber coated with electrically conductive polymer. Text. Res. J. No.74. P.924-937.

Yang, B. \& Tao, X.M. (2008). Effect of Tensile Condition and Textile Structure on Resistance Response of Stainless Steel Fibers Fabric. Rare Metal Materials and Engineering. No.37(2).

Yang, B., Tao, X.M. \& Yu, J.Y. (2006). A Study on the Relation between Resistance and Strain Based on Stainless Steel Fabric. Rare Metal Materials and Engineering. No.35(1). P.97-99.

Zhang, H., Tao, X.M., Wang, S.Y. \& Yu, T.X. (2005). Electro-mechanical properties of knitted fabric made from conductive multi-filament yarn under unidirectional extension. Text. Re. J. No.75. P.598.

Zhang, L., Song, G.L. \& Yang, K. (2008). Study on Knittability of Conducting Knitted Fabric. Journal of Tianjin Polytechnic University. No.5.

Table 1. Specifications of conductive yarns and conductive knitted fabrics

\begin{tabular}{|c|c|c|c|c|c|c|c|}
\hline Material & $\begin{array}{c}\text { Base } \\
\text { material }\end{array}$ & $\begin{array}{c}\text { Diameter } \\
(\mathrm{mm})\end{array}$ & $\begin{array}{c}\text { Stretching } \\
\text { rate }(\%)\end{array}$ & $\begin{array}{c}\text { Electric } \\
\text { conductivity } \\
\left(\Omega . \mathrm{cm}^{-1}\right)\end{array}$ & $\begin{array}{c}\text { Amount of } \\
\text { multifilament }\end{array}$ & $\begin{array}{c}\text { Fabric } \\
\text { texture }\end{array}$ & $\begin{array}{c}\text { Spec of } \\
\text { fabrics } \\
(\mathrm{cm} \times \mathrm{cm})\end{array}$ \\
\hline $\begin{array}{c}\text { Silver-coated } \\
\text { fibers }\end{array}$ & Chinlon & 0.020 & 26 & $10^{1} \sim 10^{2}$ & 12 & $1 \times 1$ Rib & $12 \times 6$ \\
\hline
\end{tabular}


Table 2. Test table of electric organ

\begin{tabular}{|c|c|c|c|c|c|}
\hline Pressing State & 1 & 2 & 3 & 4 & 5 \\
\hline $\mathrm{U}(\mathrm{mV})$ & 19 & 15 & 11 & 9.42 & 5.0 \\
\hline $\mathrm{R}(\Omega)$ & 20 & 15 & 10.4 & 7.8 & 4.7 \\
\hline $\mathrm{I}(\mathrm{A})$ & 0.95 & 1 & 1.06 & 1.2 & 1.01 \\
\hline
\end{tabular}

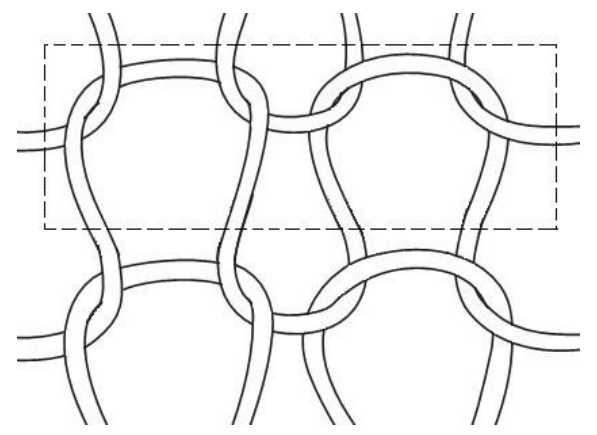

Figure 1. Geometrical Unit of $1 \times 1$ Rib Structure

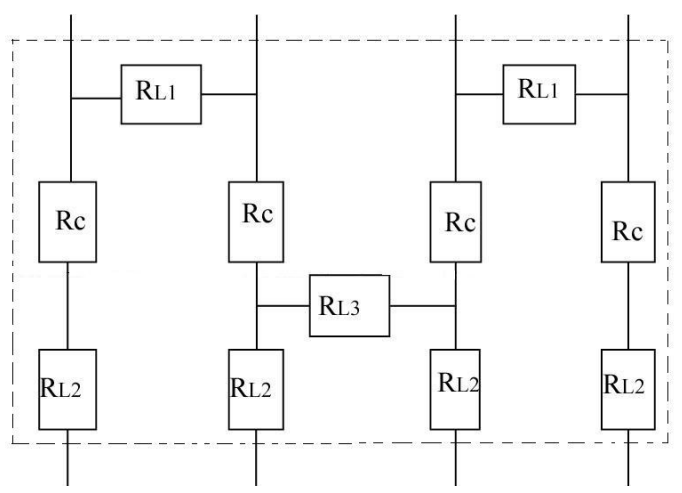

Figure 2. Model of Resistance Unit

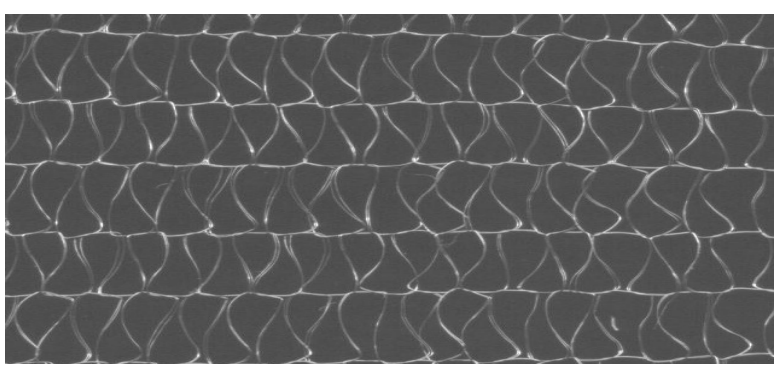

Figure 3. Conductive Knitted Fabrics Knitted by Silver-coated Yarns

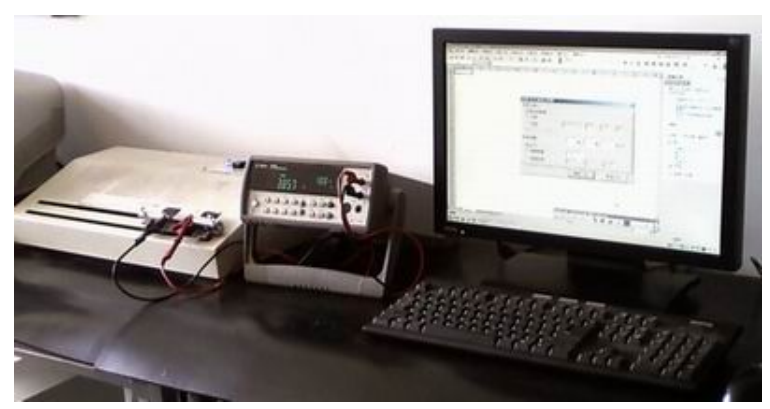

Figure 4. Test System 


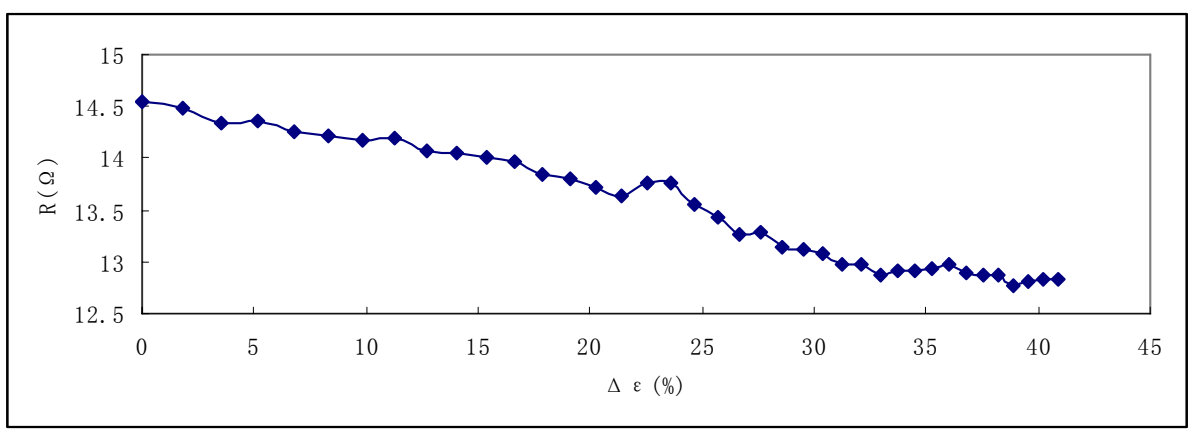

Figure 5. Change of the Silver-coated Conductive Fiber Fabrics Resistance with Stretching

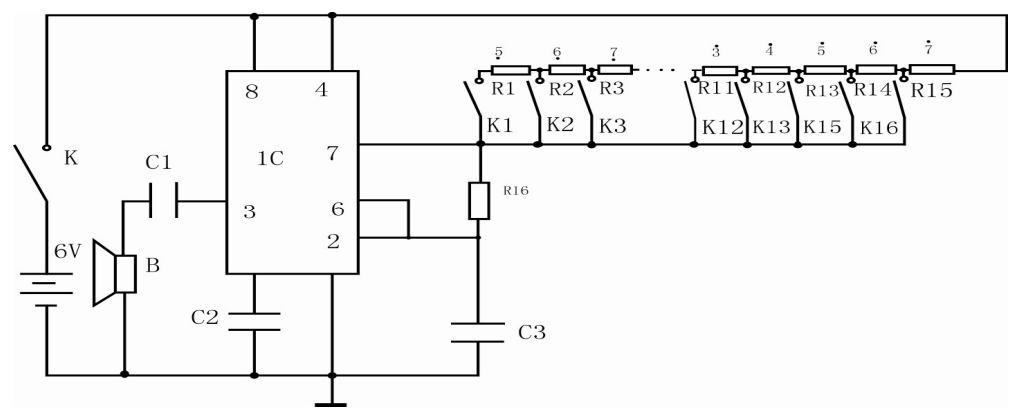

Figure 6. Circuit Principle of Electric Organ

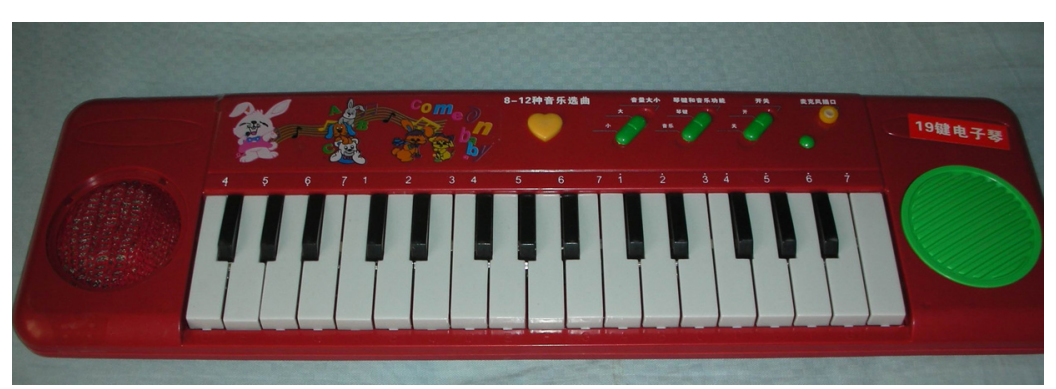

Figure 7. Converted Electric Organ 